Check for updates

Cite this: J. Mater. Chem. B, 2018, 6, 4665

\section{Switchable presentation of cytokines on electroactive polypyrrole surfaces for hematopoietic stem and progenitor cells $\dagger$}

\author{
Johanna Baumgartner, (D) a Jan-Ingvar Jönsson (D) ${ }^{b}$ and Edwin W. H. Jager (D) *a
}

Received 21st March 2018, Accepted 25th June 2018

DOI: $10.1039 / c 8 t b 00782 a$

rsc.li/materials-b

\begin{abstract}
Hematopoietic stem cells are used in transplantations for patients with hematologic malignancies. Scarce sources require efficient strategies of expansion, including polymeric biomaterials mimicking architectures of bone marrow tissue. Tissue microenvironment and mode of cytokine presentation strongly influence cell fate. Although several cytokines with different functions as soluble or membranebound mediators have already been identified, their precise roles have not yet been clarified. A need exists for in vitro systems that mimic the in vivo situation to enable such studies. One way is to establish surfaces mimicking physiological presentation using protein-immobilization onto polymer films. However these films merely provide a static presentation of the immobilized proteins. It would be advantageous to also dynamically change protein presentation and functionality to better reflect the in vivo conditions. The electroactive polymer polypyrrole shows excellent biocompatibility and electrochemically alters its surface properties, becoming an interesting choice for such setups. Here, we present an in vitro system for switchable presentation of membrane-bound cytokines. We use interleukin IL-3, known to affect hematopoiesis, and show that when immobilized on polypyrrole films, IL-3 is bioavailable for the bone marrow-derived FDC-P1 progenitor cell line. Moreover, IL-3 presentation can be successfully altered by changing the redox state of the film, in turn influencing FDC-P1 cell viability. This novel in vitro system provides a valuable tool for stimuli-responsive switchable protein presentation allowing the dissection of relevant mediators in stem and progenitor cell behavior.
\end{abstract}

\section{Introduction}

Hematopoietic stem cells (HSC) represent a population of progenitor cells that can be found in the bone marrow (BM), the placenta, and in umbilical cord blood (UCB). They are able to replenish all mature blood lineages and have emerged as suitable tools for transplantation in patients with hematologic malignancies. ${ }^{1}$ However, since the number of HSCs that can be obtained from suitable tissues is very low, strategies to produce a sustainable supply of HSC by ex vivo expansion are of great interest. ${ }^{2}$ Many protocols that have been established to expand UCB-derived HSC ex vivo, involve suspension culture in the presence of different early acting cytokines including stem cell factor (SCF), Ftl-3 ligand (Flt3L), interleukin-3 (IL-3), as well as thrombopoietin (TPO), and granulocyte-colony stimulating factor (G-CSF). However, these protocols neglect the nature of

\footnotetext{
${ }^{a}$ Department of Physics, Chemistry and Biology (IFM), 58183 Linköping, Sweden. E-mail: edwin.jager@liu.se

${ }^{b}$ Department for Clinical and Experimental Medicine (IKE), 58183 Linköping, Sweden

$\dagger$ Electronic supplementary information (ESI) available. See DOI: 10.1039/c8tb00782a
}

the culturing surface that might significantly influence the outcome of the expansion. It has been recognized that in the bone marrow HSCs interact with the extracellular microenvironment. Moreover, HSC function depends on intrinsic cell regulation that is modulated by external signals, including cytokines and extracellular matrix (ECM) molecules. ${ }^{3}$ Several compounds with the ability to expand HSC populations and to regulate hematopoiesis have been identified, but still the precise role of these compounds is not well understood. ${ }^{1}$

In vivo, HSC reside in specialized niches in the BM that provide crucial signals to mediate self-renewal, differentiation, migration, and homing. ${ }^{2}$

Controlled expression and distribution of cytokines has found increasing support in studies that look particularly at their binding properties and modes of expression. ${ }^{4}$ Several cytokines that are important regulators of hematopoiesis have been shown to not only be secreted but to also exist either bound to a membrane or the ECM. ${ }^{4}$ Recently, numerous studies have identified SCF as an important hematopoietic microenvironmental regulator which exists in both soluble (SSCF) and membranebound (tmSCF) form that exert different functions. ${ }^{5}$ While sSCF mainly promotes progenitor cell development by synergistically 
modulating growth factor responsiveness, tmSCF directly mediates cell proliferation and acts as a ligand for cell-to-cell interactions. ${ }^{6}$ In a study by Long et al. SCF that was immobilized on tissue culture plastic directly functioned as a stimulating factor in the absence of other cytokines, suggesting that changes occurring during the binding of SCF allow the cytokine to function as a stimulating factor, possibly mimicking the membrane-bound form of this molecule. ${ }^{5}$ However, although SCF has been shown to support short-term survival and in vitro expansion of human as well as murine HSC to some extent, long-term in vitro expansion for clinical purposes has not yet been successful, leaving no doubt that there are novel or yet unrecognized factors provided within the BM niche which support HSC survival and self-renewal in vivo. ${ }^{7}$ Strikingly, the identification of those factors in a setup that mimics the physiological setting more closely, including temporal variations, remains one of the most challenging aspects of stem cell biology.

One elegant way to establish such a setup and to create an interface between HSCs and membrane-bound proteins is immobilizing the protein of interest onto polymer films. For a long time, conducting polymers have been studied in detail in regard to their applicability as coatings to promote biocompatibility, to apply mechanical stimulation or to serve as a substrate in the analysis of cells and biomolecules. ${ }^{8-11}$ Especially due to their flexibility at the level of synthesis and their nonvolatile character, they have become suitable candidates for promoting cell-adhesion. ${ }^{12}$ Among the great number of conducting polymers being investigated and used for biomedical applications, polypyrrole (PPy) has emerged as a particularly promising candidate. Polypyrrole offers several advantages such as chemical stability, ease of polymerization, as well as high biocompatibility with mammalian cells. ${ }^{13}$

In the biomedical field, numerous applications make use of PPy-based films for detection and analysis of biomolecules. For instance, highly sensitive label-free sensors for DNA and other biomolecules using electroactive PPy films have been developed. ${ }^{14-16}$ Similarly, biosensors using aptamers immobilized onto PPy films have been established for pathogen detection. ${ }^{17,18}$ Moreover, due to its beneficial electroactive surface properties, conducting polymer films can also be used to serve as drugdelivery systems that release distinct molecules and drugs on request or to alternate the presentation of immobilized molecules in a stimuli-responsive manner. ${ }^{19,20}$ In this regard, stimuli such as temperature, light, magnetic field and electrical potential can alter and manipulate the surface properties of a film and thus change and control availability, function or activity of immobilized biomolecules on the surfaces, thereby representing promising tools for biomedical and biotechnological applications, especially to develop dynamic surfaces that can mimic in vivo situations. ${ }^{21-23}$

The object of this study was to establish an in vitro system or microphysiological device for presentation of membrane-bound cytokines using electroactive PPy surfaces that will allow for dissecting the involved mechanisms and identifying the cellular mediators that potentially regulate stem cell survival, self-renewal and proliferation. Moreover, to mimic biological stimuli, the electroactive properties of the PPy film will be used to establish a switchable presentation of the immobilized cytokine of interest based on alterations in redox potential. Although IL-3 exerts its function as a soluble mediator, we used the IL-3 dependent mouse bone marrow-derived progenitor cell line FDC-P1 as a proof-of-concept model. The rationale is merely that this cell line has been used in many previous studies to study the impact of cytokines on proliferation and cell viability. Binding IL-3 to a defined switchable surface provides an appealing model to mimic cell-to-cell interactions in the complex environment of the bone marrow. The model will enable the development of an in vitro culture system for more efficient and controlled shortand long-term expansion of HSCs and progenitor cells.

To functionalise conjugated polymers typically adsorption ${ }^{9,24}$ or entrapment/doping of the biomolecule ${ }^{25-29}$ is used. Covalent binding to conjugated polymer has been done using EDC-NHS coupling to a carboxylic-group on the polymer backbone ${ }^{18,30}$ or using arylazido chemistry. ${ }^{31}$ However, an issue with synthesizing conjugated polymers from a mixed monomer solution (pyrrole and carboxylic-acid-substituted-pyrrole) is that it gives poor control over resulting film with regards of the ratio of pyrrole to $\mathrm{COOH}$-pyrrole monomers. The ratio of monomers in the film is not the same as the ratio in solution and unpredictable due to the different reactivity of the monomers. ${ }^{32}$ Also, such modified conjugated polymers result in low conductive films. ${ }^{33,34}$ Therefore, we have chosen to covalently attach the cytokines to dopants instead. We used dopants with two $\mathrm{COOH}$ groups to ensure that there is always a $\mathrm{COOH}$ group available for the coupling chemistry, in contrast to dopants with one $\mathrm{COOH}$ group ${ }^{33-35}$ and one other anionic group, where either the $\mathrm{COO}^{-}$or the other anionic group will compensate the polaron on the PPy backbone.

\section{Results}

\section{Characterization of polymer films}

Infrared and electrochemical characterization. Potentiostatic electrosynthesis was used to deposit a film of PPy (Fig. 1a for structure) and dopant molecules, such as anions or negatively charged biomolecules onto gold coated electrodes. Due to the positive charge on the polymer backbone, the anionic dopant molecule is incorporated during the synthesis in order to maintain charge neutrality. ${ }^{19}$ In this work, different dopants and their effects on film characteristics were compared. The selected dopants oxalic acid (OXA), succinic acid (SUCA) and suberic acid (SUBA) belong to the family of carboxylic acids and vary in length of their carbon chain backbone so that we can tailor the distance between the cytokine and surface (Fig. 1a). The carboxylic dopants where chosen because proteins can be immobilized onto the carboxyend using NHS-EDC coupling. PPy films that were generated in the presence of different dopants showed differences in infrared spectra as well as distinct electrochemical properties, as can be seen in attenuated total reflectance (ATR), cyclic voltammetry (CV) and impedance measurements of the films.

The presence of carboxylic acid groups in the PPy films was verified with ATR measurements (Fig. 1b). Films containing dopants with carboxyl groups which can be used for chemical grafting display characteristic differences in their ATR spectra 


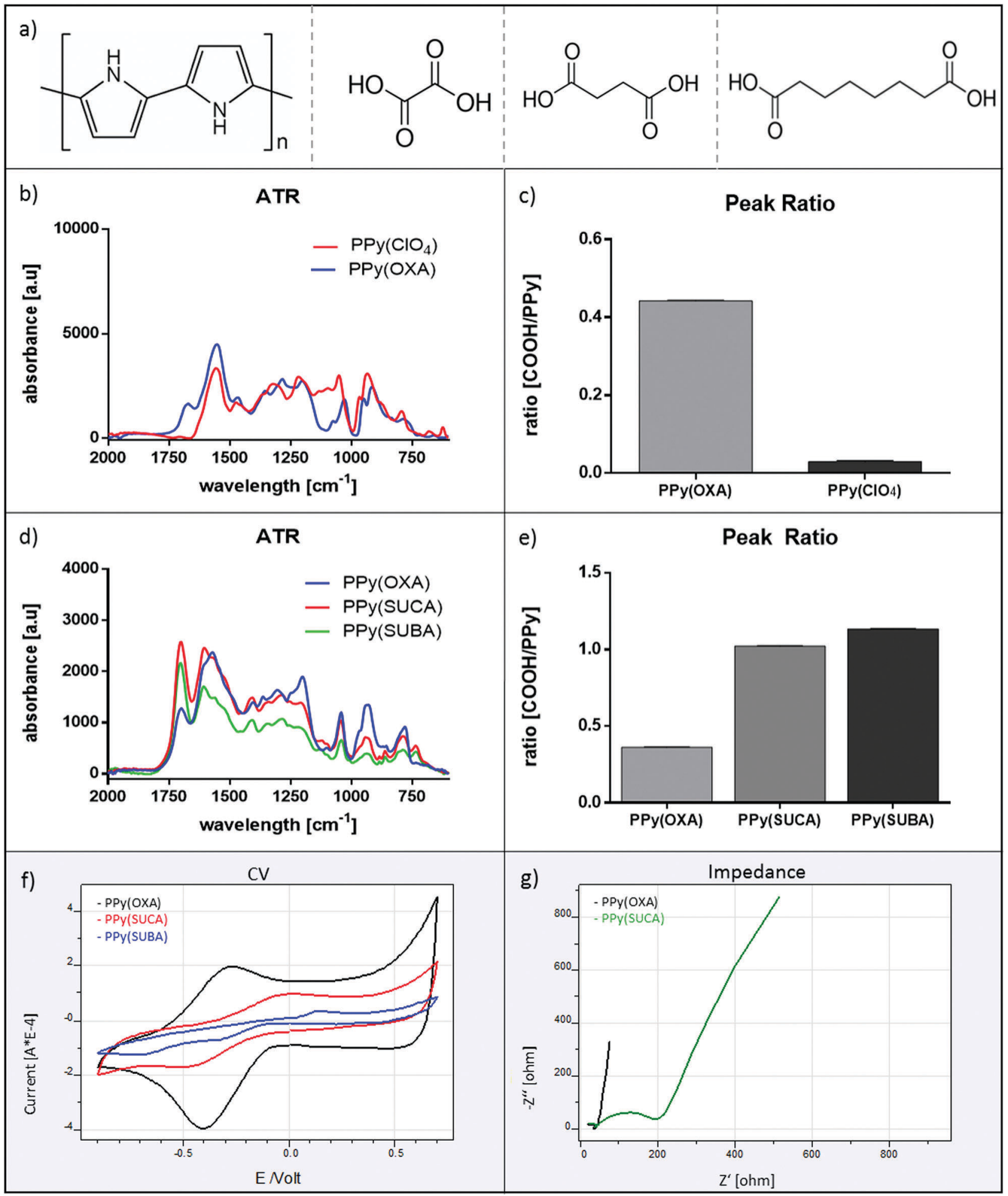

Fig. 1 Structure of Polypyrrole (PPy), used dopants as well as infrared and electrochemical characterization of doped PPy films. (a) Chemical structures of PPy and the used dopants. From left to right: PPy, oxalic acid (OXA), succinic acid (SUCA), suberic acid (SUBA). (b) ATR measurements of PPy(ClO ${ }_{4}$ ) and PPy $(O X A)$. (c) COOH/PPy peak ratio analysis of PP $\left(\mathrm{ClO}_{4}\right)$ and PPy $(\mathrm{OXA})$ films. (d) ATR measurements of PPy films doped with OXA, SUCA and SUBA. (e) $\mathrm{COOH} /$ PPy peak ratio analysis of PPy films doped with OXA, SUCA and SUBA. (f) Cyclic voltammetry of PPy films doped with OXA, SUCA and SUBA recorded in $0.1 \mathrm{M} \mathrm{NaCl}$. Scan rate: $100 \mathrm{mV} \mathrm{s}^{-1}$. (g) Impedance measurements for PPy(OXA) and PPy(SUCA) films recorded in $0.1 \mathrm{M} \mathrm{NaCl}$.

compared to films synthesized with dopants that do not contain a carboxylic acid. The peak at $1680 \mathrm{~cm}^{-1}$, which is associated with the $\mathrm{C}=\mathrm{O}$ stretching mode of the carboxylic groups,${ }^{15}$ can only be observed in PPy films doped with different 
carboxylic acids such as OXA, SUCA or SUBA, but not in those doped with other dopants such as lithium perchlorate $\left(\mathrm{LiClO}_{4}\right)$. The broad band around $1550 \mathrm{~cm}^{-1}$ is the characteristic absorption frequency for the double bond vibration of the pyrrole ring. ${ }^{12,19}$ The ratios between the pyrrole (at $1550 \mathrm{~cm}^{-1}$ ) and the carboxyl $(\mathrm{COOH})$ peaks (at $1680 \mathrm{~cm}^{-1}$ ) were determined as the ratios between the absolute peak heights and were significantly higher in carboxyl group containing PPy(OXA) films (0.44) as compared to $\mathrm{PPy}\left(\mathrm{ClO}_{4}\right)$ films (0.03, Fig. 1c). Moreover, ATR measurements revealed that the carboxylic acid content varied among the films generated with different carboxylic acid dopants (Fig. 1d). It can be observed that the longer the carbon backbone of the carboxylic acid dopant, the higher the $\mathrm{C}=\mathrm{O}$ stretching-associated peak in the ATR-spectrum of the PPy films, suggesting increased doping with larger carboxylic acid molecules. The peak ratios were observed to increase for the differently doped films, depending on the size of the carboxylic acid (Fig. 1e). PPy(OXA) films displayed a COOH/PPy peak ratio of 0.36 , PPy(SUCA) films one of 1.02 and PPy(SUBA) films had a peak ratio of 1.13. Furthermore, a COOH/PPy peak ratio analysis of PPy films of different thicknesses revealed that the relative amount of carboxyl groups present in the PPy film does only change to a small extent with increasing thickness, and is the same in thin films up to $100 \mathrm{~nm}$, indicating a uniform doping of the film that is not restricted to the superficial layers of the polymer film (Fig. S1a and b, ESI $\dagger$ ). Next, PPy film stability in terms of dopant retention was investigated among the differently doped films (Fig. S1c, ESI $\dagger$ ) by applying a constant negative potential $(-0.5 \mathrm{~V})$ to the films for 10 minutes. PPy(SUCA) films displayed best stability, as indicated by constant $\mathrm{COOH} / \mathrm{PPy}$ peak ratios among as-fabricated and reduced films. In PPy(OXA) films a minor increase in $\mathrm{COOH} / \mathrm{PPy}$ ratio could be observed, whereas in PPy(SUBA) films, a decrease in $\mathrm{COOH} / \mathrm{PPy}$ ratio was observed after film reduction, indicating slightly less stable doping in these films. However, a significant release of dopant molecule as described elsewhere ${ }^{19}$ for studies of drug release, was observed in neither of the doped films, demonstrating that the carboxylic ions are immobile dopants similar to for instance dodecylbenzene sulfonic acid (DBS). ${ }^{36,37}$

$\mathrm{CV}$ and impedance measurements of differently doped PPy films were recorded in a $0.1 \mathrm{M}$ sodium chloride $(\mathrm{NaCl})$ solution to allow for better comparison between the different films. As seen in Fig. 1f, the voltammograms for films doped with OXA, SUCA and SUBA showed significant differences in redox properties. PPy films doped with OXA and SUCA displayed clear oxidation and reduction peaks. Oxidation of $\mathrm{PPy}(\mathrm{OXA})$ films occurred at a potential of $-0.25 \mathrm{~V}$ and reduction occurred at a potential of $-0.4 \mathrm{~V}$. As for PPy(SUCA), the redox window was broader, with an oxidation peak around $0 \mathrm{~V}$ and a reduction peak at $-0.5 \mathrm{~V}$. The $\mathrm{CV}$ for the PPy(SUBA) film was more flattened out with a weak oxidation peak around $0.15 \mathrm{~V}$ and two reduction peaks at $-0.3 \mathrm{~V}$ and $-0.7 \mathrm{~V}$. When comparing the CVs of the differently doped PPy films, the one for $\mathrm{PPy}(\mathrm{OXA})$ displays the highest current, indicating highest charging capacity, followed by the PPy(SUCA) film. However, the PPy(SUBA) film was determined only weakly electroactive as the current was very low, possibly due to weak adherence of the film on the gold electrode (compare with the scanning electron microscopy (SEM) analysis, Fig. 2e and f). As the CV strongly correlates with the thickness of the film (Fig. S1d, ESI $\dagger$ ), we aimed to obtain the same thickness for the differently doped polymer films by optimizing the time for polymerization until the same colour of the film could be obtained for all the films. The approximate correspondence to thickness was determined by the colour of the films with light brown to copper indicating a film thickness of $40-80 \mathrm{~nm} .^{36}$

Impedance measurements to further validate the presence of carboxyl groups in the film showed similar results regarding the conductivity of the films. The presence of carboxyl groups in the film is expected to introduce a steric and electrostatic hindrance that affects the conjugation in the polymeric film. ${ }^{18}$ In line with that, PPy(SUCA) films displayed lower intrinsic conductivity than the $\mathrm{PPy}(\mathrm{OXA})$ films, as seen in higher impedances, as a result of an increase in resistance in these films (Fig. 1g). In PPy(SUBA) films the impedance recorded was very low (Fig. S1e, $\mathrm{ESI} \dagger$ ), possibly due to insufficient adherence and cracking of the film on the gold electrode, and therefore not included for the impedance analysis.

Topographical characterization. Being of great importance in tissue engineering and biomedical applications, the surface properties of the differently doped PPy films including topographical features such as film roughness and wettability were determined with scanning electron microscopy (SEM) analysis, surface profilometry and water contact angle measurements.

In Fig. 2, SEM pictures of the doped PPy films can be seen. PPy(OXA) and PPy(SUCA) films are smooth adherent and display similar topographical globular features, as described in literature, ${ }^{38}$ as well as comparable and homogenous surface roughness (Fig. 2a-d). Notably, in PPy(SUBA) films, apart from increased roughness and wave-like formation of the polymer film, indicating insufficient adherence of the film to the gold electrode, cracks spreading over the whole film can be observed (Fig. 2e and f). In line with what could be observed in the SEM pictures, surface profilometry confirmed similar as well as lower roughness of PPy(OXA) films (10.4 nm) and PPy(SUCA) films (9.69 nm) as compared to PPy(SUBA) films (49.28 nm, Fig. 2g). Although surface profilometry can in principle also be performed to determine film thickness, these measurements could not be conducted for the thin (40-80 nm) PPy films used in this experiment and thickness was merely assumed according to the film colour.

To investigate the surface energy, wettability of the PPy films was determined using water contact angle (WCA) measurements as described in the Experimental section. In agreement with the literature, ${ }^{39}$ carboxyl groups present in the film decreased the WCA and thus enhanced hydrophilicity. It can be observed in Fig. $2 \mathrm{~h}$ that the WCA for the differently doped films decreases with increasing amount of carboxyl groups present. In this regard, $\mathrm{PPy}(\mathrm{OXA})$ films display lowest wettability $\left(64.6^{\circ}\right)$, followed by PPy(SUCA) films $\left(56.1^{\circ}\right)$ and PPy(SUBA) films $\left(14.6^{\circ}\right)$ display highest wettability, compared to PPy films that do not contain any carboxylic groups but were polymerized in a $0.1 \mathrm{M}$ sodium dodecylbenzene sulfonate solution PPy(DBS) and displayed a higher WCA $\left(79.5^{\circ}\right.$ ) (Fig. S2a, ESI $\dagger$ ). Similar WCA for PPy(DBS) in the range between $78.6^{\circ}$ to $87.2^{\circ}$, depending on the time of film polymerization, were also described in literature. ${ }^{12}$ 


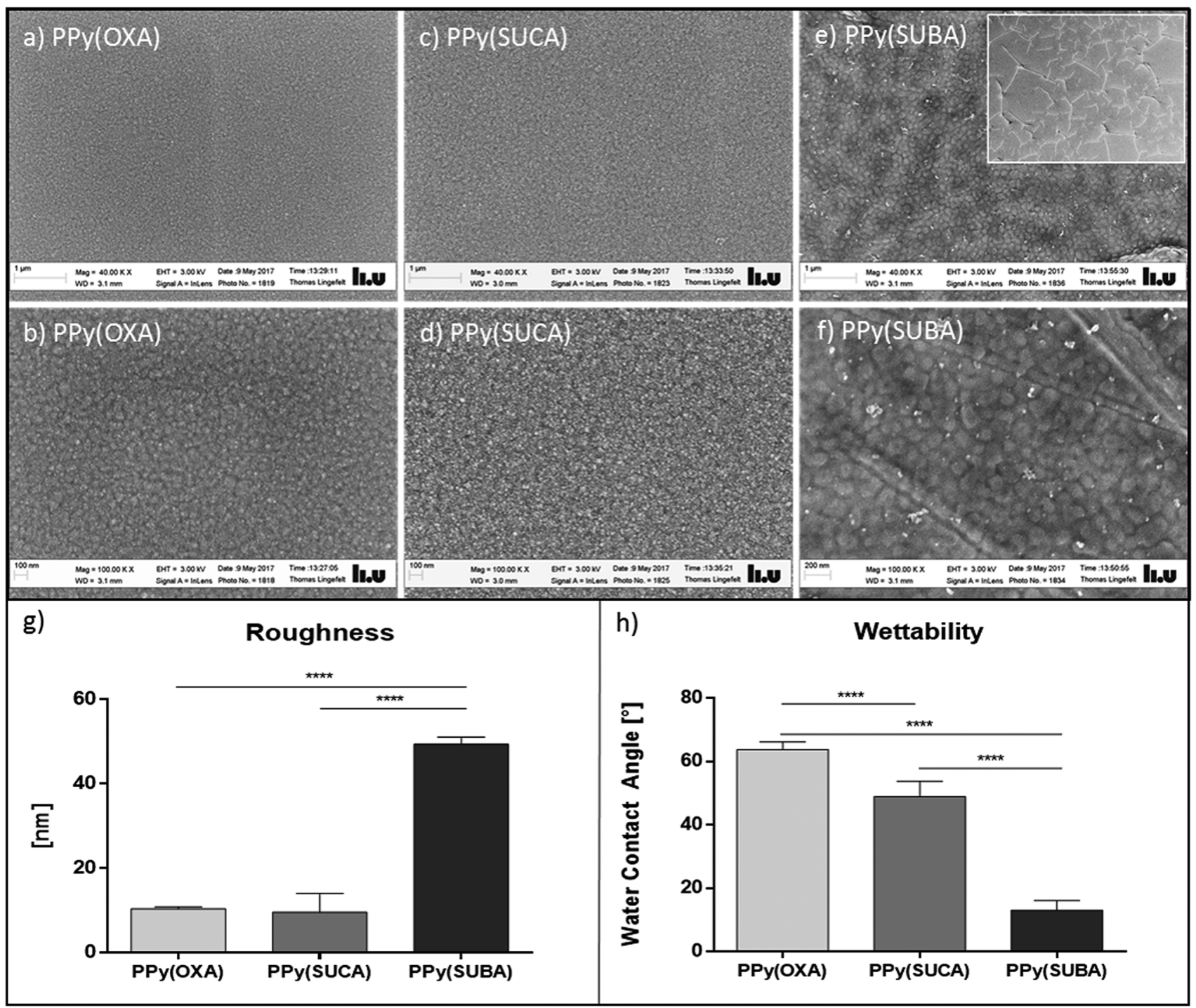

Fig. 2 Topographical characterization of differently doped PPy films. (a and b) SEM pictures of PPy(OXA) films at 40000 -fold and 100000 -fold magnification. (c and d) SEM pictures of PPy(SUCA) films at 40000 -fold and 100000 -fold magnification. (e and f) SEM pictures of PPy(SUBA) films at 40000 -fold and 100000 fold magnification. The inset in (e) shows a PPy(SUBA) film at 1000-fold magnification. (g) Roughness of PPy films doped with OXA, SUCA and SUBA as recorded by surface profilometry $(n=3)$. (h) Wettability of differently doped PPy determined by WCA measurements $(n=3)$. ${ }^{* \star *} p<0.0001$.

However, the high wettability of the PPy(SUBA) films could also be a result of the additional surface roughness and might not necessarily only be attributable to the increased carboxyl group content in these films. Due to unsatisfactory electrochemical and topographical features PPy(SUBA) films were therefore not considered for any further experiments.

Immobilization of IL-3. To covalently bind the protein of interest to the conducting, $N$-(3-dimethylaminopropyl)- $N^{\prime}$-ethylcarbodiimide hydrochloride (EDC)/ $N$-hydroxysuccinimide (NHS) coupling chemistry can be used. EDC/NHS chemistry represents a coupling method with which a covalent bond can be generated between an amine and a carboxyl group. Activation of carboxyl groups with the EDC/NHS solution results in the formation of active, instable intermediate esters that are stabilized with NHS and can be covalently linked to amine groups in the biomolecule to be immobilized. ${ }^{40}$
To validate the immobilization of the protein on differently doped PPy films, impedance spectra and WCA were determined prior and post incubation with IL-3. As seen in Fig. 3a and b, impedances are higher in PPy(OXA) and PPy(SUCA) films incubated with EDC/NHS solution and after incubation with IL-3. This can be explained by a decrease in film conductivity induced by steric and electrochemical hindrance, ${ }^{17,18}$ which is caused by the formed reactive ester after activation with the EDC/ NHS coupling solution. Similarly, we observed the expected attenuation in electroactivity due to blocking properties of the immobilized protein layer. $^{12}$

WCA decreased after incubation with the EDC/NHS coupling solution for OXA and SUCA-doped PPy films (Fig. 3c). Interestingly, subsequent incubation with IL-3 again affected the wettability of the films by increasing the WCA. In line with the literature, ${ }^{41,42}$ films with higher carboxyl group content displayed a stronger 

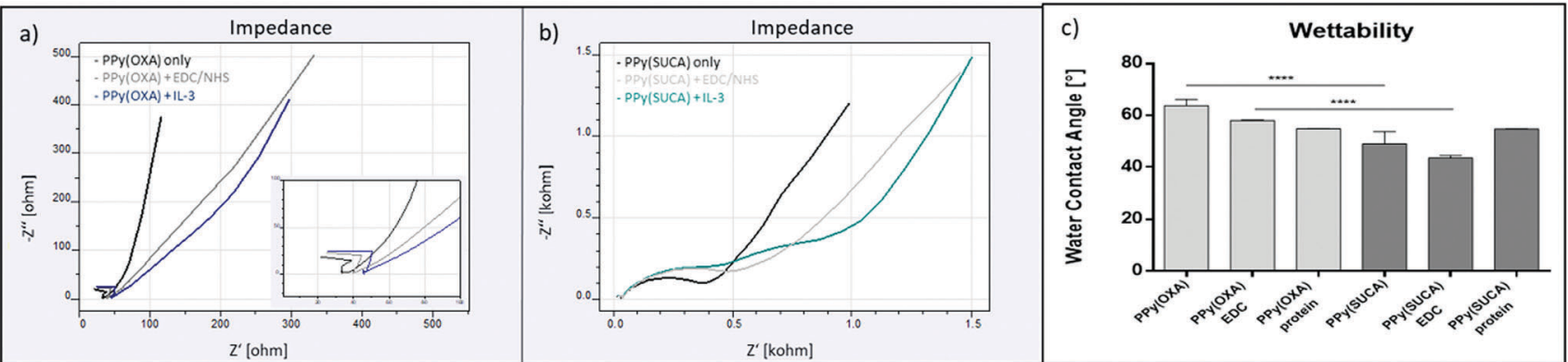

Fig. 3 Film characterization by impedance and WCA measurements after IL-3 immobilization. (a) Electrochemical impedance measurement of bare PPy(OXA) films, PPy(OXA) films after EDC/NHS activation and PPy(OXA) films after EDC/NHS activation and subsequent IL-3 immobilization. (b) Electrochemical impedance measurement of bare PPy(SUCA) films, PPy(SUCA) films after EDC/NHS activation and PPy(SUCA) films after EDC/ NHS activation and subsequent IL-3 immobilization. (c) Wettability of PPy(OXA) (light grey) and PPy(SUCA) films (dark grey) before and after EDC/NHS activation and IL-3 immobilization $(n=3) .{ }^{* * *} p<0.0001$.

decrease in WCA, i.e. showed increased wettability, as compared to films with lower carboxyl group content. In this regard, in PPy(OXA) films a higher WCA $\left(58.0^{\circ}\right)$ could be observed as compared to PPy(SUCA) films $\left(43.5^{\circ}\right)$. After incubation with IL-3, wettability of the PPy films decreased to a similar level. There was no difference observable for the WCA of PPy(OXA) and PPy(SUCA) films after incubation with the protein for 2 hours $\left(54.8^{\circ}\right.$ vs. $\left.54.7^{\circ}\right)$, indicating comparable amounts of immobilized protein on both PPy films, regardless the used dopant (Fig. 3c).

Biocompatibility of polymer films. To evaluate biocompatibility of the polymer films, OXA and SUCA doped PPy films were incubated with FDC-P1 cells for 24 and 48 hours and subsequently stained with Annexin V for flow cytometric detection of apoptotic cells. The FDC-P1 cell line is an immortalized, nontumorigenic, hematopoietic progenitor cell line that depends on IL-3 for survival and proliferation. ${ }^{43}$ In the absence of IL-3, FDC-P1 cells die rapidly by apoptosis. Flow cytometric analysis showed good biocompatibility for PPy(OXA) and PPy(SUCA) films (both $>97 \%$ viability after $24 \mathrm{~h}$ and $48 \mathrm{~h}$, Fig. $4 \mathrm{a}$ ) and no significant difference to the control $(98.1 \%$ after $24 \mathrm{~h}$ and $97.7 \%$ after $48 \mathrm{~h}$ ) when cultivated with FDC-P1 cells and IL-3 in medium. PPy films doped with $\mathrm{LiClO}_{4}$ and NaDBS, as well as pure gold electrodes showed similar results (Fig. S2b, ESI $\dagger$ ), indicating that neither the substrate, nor the polymer, nor the selected dopants interfered with cell viability.

Bioavailability and switching of IL-3. As FDC-P1 cells strongly depend on IL-3 for survival, these cells were chosen as a tool to verify successful IL-3 immobilization and bioavailability. For bioavailability studies $\mathrm{PPy}(\mathrm{OXA})$ and $\mathrm{PPy}(\mathrm{SUCA})$ films were investigated. For protein switching studies only PPy(SUCA) films were used.

Bioavailability of IL-3. Bioavailability studies were performed on IL-3 deprived FDC-P1 cells for 24 and 48 hours. In Fig. 4 b, the viability of FDC-P1 cells after cultivation with the doped modified PPy films is shown, indicating successful immobilization and presentation of the protein to the cells. It can be observed that IL-3 deprivation results in rapid cell death already after 24 hours (15.9\% viability). The effect of IL-3 starvation is even more pronounced after 48 hours (3.4\%), suggesting that the starvation protocol effectively removes all residual IL-3 from the cells.
The modified polymer surfaces with immobilized IL-3 preserved cell viability at a similar level as replenishment with soluble recombinant IL-3 $\left(0.1 \mathrm{ng} \mathrm{ml}^{-1}\right)$ did for 24 and 48 hours of incubation with the films (92.7\% and $90.2 \%$, Fig. 4 b). For 24 and 48 hours of incubation there was no significant difference between PPy(OXA)-IL-3 films (95.2\% and 89.0\%) and PPy(SUCA)IL-3 films (94.9\% and $89.4 \%$ ) regarding their effect on cell viability, indicating a comparable amount of protein immobilized on these two films. Moreover, viability of the cells incubated with the IL-3-modified PPy(OXA) and PPy(SUCA) films was comparable with but slightly lower than the viability of FDC-P1 cells that were not deprived of IL-3 but cultivated with IL-3-enriched medium for 24 and 48 hours (98.2\% and 98.0\%, Fig. S2c, ESI $\dagger$ ). Furthermore, to evaluate non-specific binding of IL-3 on the polymer surfaces, PPy(SUCA) films were incubated with IL-3 but without EDC/NHS crosslinking solution. Fig. S2d (ESI $\dagger$ ) shows viability of FDC-P1 cells when incubated with PPy(SUCA) films after 24 and 48 hours. The FDC-P1 cells were incubated with films treated with IL-3 only, and not subjected to the crosslinking solution, and compared to control setup as well as no IL-3 control. Cells incubated with the control setup showed high viability (98.2\% and 92.8\%), whereas cells on films without IL-3 showed high apoptosis after 24 and 48 hours $(9.7 \%$ and $7.7 \%)$. FDC-P1 cells incubated with films treated with IL-3 only displayed higher viability compared to cells on films without IL-3 (26\% and $28.7 \%$ ), indicating that the protein is to some extent adsorbed onto the films via nonspecific binding. For subsequent switching studies the PBS washing protocol was not further refined, as the adsorbed protein is assumed to strongly stick on the film and believed to be influenced by changes in electrochemical properties of the film as well.

Switchable presentation of IL-3. After protein immobilization and bioavailability had been verified, the effect of redox state alterations on protein presentation was investigated. FDC-P1 cells were incubated with PPy(SUCA) films in the as fabricated state (no potential applied) at constant positive ( $0.2 \mathrm{~V}$, oxidation), or constant negative $(-0.7 \mathrm{~V}$, reduction) potential for 24 or 48 hours. The redox potentials were selected based on the $\mathrm{CV}$ for the PPy(SUCA) film that was recorded in $\mathrm{NaCl}$ as previously described (in Section: Infrared and electrochemical characterization). 


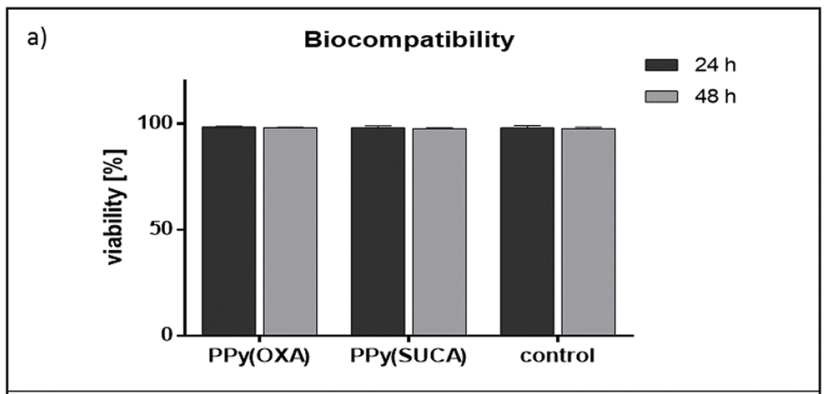

b) Viability after starvation and IL-3 replenishment

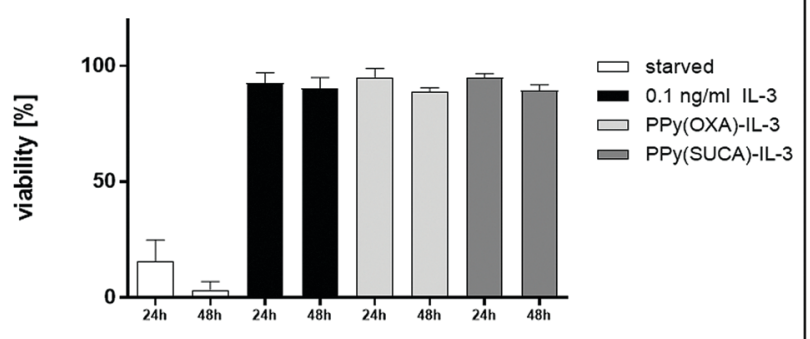

c) Viability after switching of PPy(SUCA) films
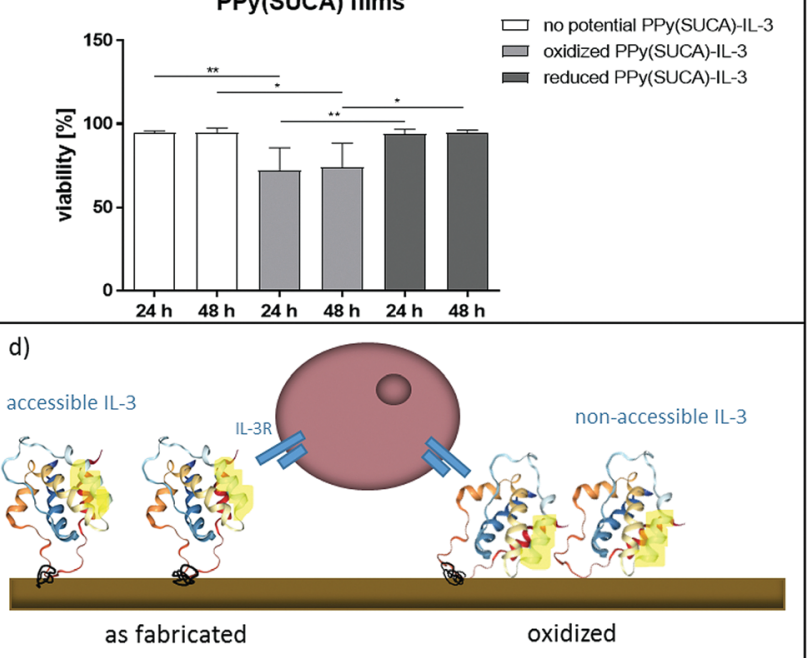

Fig. 4 Biocompatibility, Bioavailability and Switching of PPy films. (a) Viability of FDC-P1 cells cultivated in presence of soluble IL-3 with PPy(OXA), PPy(SUCA) or in a plain culture dish without polymer films (control) for 24 and 48 hours as determined by Annexin $V$ staining and subsequent flow cytometric analysis $(n=3)$. (b) Viability of FDC-P1 cells that have been deprived of IL-3 (starved) after incubation with polymer samples or soluble IL-3 for 24 and $48 \mathrm{~h}$ determined by trypan blue exclusion staining $(n=3)$. Starved cells were deprived of IL-3, $0.1 \mathrm{ng} \mathrm{ml}^{-1}$ indicates the concentration used for replenishment of starved FDC-P1 cells with recombinant IL-3 in solution and PPy(OXA) and PPy(SUCA) indicate starved FDC-P1 cells incubated with the polymer film-immobilized IL-3. (c) Viability of FDC-P1 cells after switching of the redox state of PPy(SUCA) films for 24 and $48 \mathrm{~h}$ $(n=4)$. No potential indicates cultivation of surface modified PPy(SUCA) films in as fabricated state and oxidized and reduced indicated cultivation of FDC-P1 cells in the presence of surface modified PPy(SUCA) films kept either at constant positive $(0.2 \mathrm{~V})$ or negative $(-0.7 \mathrm{~V})$ potential. ${ }^{*} p<0.05$ ${ }^{* *} p<0.01$. (d) Conceptional illustration of the proposed mechanism for IL-3 switching upon changing the redox state of the PPy film. We assume that putative binding sites for the IL-3 receptor (marked yellow) are not accessible upon oxidation of the film.
Fig. 4c depicts the viability of FDC-P1 cells cultivated for 24 or 48 hours in the presence of as fabricated, reduced or oxidized PPy(SUCA) films. It can be observed that after 24 and 48 hours cells cultivated with PPy(SUCA) films kept in a reduced state display similar ( $94 \%$ and $94.3 \%$ ) viability as those that were cultivated with as fabricated films (94.5\% and $94.5 \%)$. Interestingly, FDC-P1 cells cultivated in the presence of PPy(SUCA) films kept in an oxidized state show significantly reduced viability after 24 hours (71.8\%) and 48 hours (73.8\%). This indicates that presentation of IL-3 on the films to the cells is impaired, possibly due to stronger electrostatic interactions between the polymer surface and the protein ${ }^{20}$ which leads to changes in protein conformation or accessibility, that ultimately reduces bioavailability of the protein. Strikingly, changes in the redox potential alone did not influence FDC-P1 viability, as experiments with PPy(NaDBS) and soluble IL-3 show (Fig. S2e, ESI + ). FDC-P1 cells were incubated with PPy(NaDBS) films without any potential applied as well as oxidized (kept at a potential of $0.2 \mathrm{~V}$ ) or reduced (kept at a potential of $-0.7 \mathrm{~V}$ ) films. There was no significant difference in viability after 24 and 48 hours between as fabricated (97.3\% and 92.3\%), oxidized ( $96 \%$ and $91 \%$ ) and reduced PPy(NaDBS) films (98.7\% and 91\%). In Fig. 4d a conceptual illustration of the proposed mechanism for protein switching is shown.

\section{Discussion}

Proteins and small molecules have important applications in biomedical research, for instance as probes to identify novel signalling pathways, tools for dissecting mechanisms, and potentially even as therapies. ${ }^{1,44}$ Future progress in the application of proteins and small molecules to improve stem cell biology will depend on progress in characterization of protein function as well as identification of their implication in important processes relevant for stem cell viability, self-renewal, proliferation, commitment and differentiation. In turn, progress in stem cell biology will allow us to identify new molecular targets for intervention and, in parallel, innovations in chemical screening will allow for the rapid generation of effective small molecules. ${ }^{1}$

HSCs that reside in bone marrow niches are provided with a wide array of cyto- or chemokines and ECM molecules which are responsible for determining HSC behaviour. ${ }^{3}$ These proteins, either in membrane-, matrix-bound or in soluble form are involved in HSC biology and the mode of presentation plays a particularly important role in determining their function. ${ }^{45,46}$ However, the exact mechanism of how these regulating elements work has yet to be elucidated and suitable platforms to investigate the implications of membrane- or matrix-bound molecules are needed.

Proteins immobilized onto polymer surfaces can mimic a natural environment of membrane- or ECM-bound proteins and not only enhance biocompatibility of a material or to promote certain cellular responses including proliferation and differentiation. . $^{11,47-49}$ In the present study, we established a new platform for matrixbound presentation of proteins to hematopoietic progenitor cells, thereby providing a novel and versatile system to evaluate cellular 
responses to matrix-bound biomolecules in a convenient and simple in vitro platform. Although IL-3 does not exist as a membrane-bound form, it is in many cases released from stromal cells adjacent to the hematopoietic cells and via direct cell-cell interactions. Thus, IL-3 provides a proof-of-concept principle in a well-defined and easy accessible cellular system.

PPy films have been shown to generally provide good biocompatibility, which depends to some extent on the choice of dopant molecule. ${ }^{50-52}$ In line with that, we could show that all PPy films used in this study, i.e. doped with OXA, SUCA and SUBA, display excellent biocompatibility when cultivated with FDC-P1 cells (Fig. 4a), thus representing suitable candidates for protein immobilization. However, due to poor material properties of PPy(SUBA) films, including weak electroactivity, extensively cracked and rough surface morphology, as well as lacking film integrity, these films were not considered relevant for more profound studies. Multiple evidences suggest that pyrrole electropolymerization strongly depends on the $\mathrm{pH}$ of the solution and alkaline electrolytes with a $\mathrm{pH}$ value higher than 7 have generally been found to interfere with electropolymerization. ${ }^{53,54}$ PPy(POXA) and PPy(SUCA) films were generated in $0.1 \mathrm{M}$ electrolyte solutions of $\mathrm{pH} 1.7$ and 2.8, respectively. It is thus not too surprising that the PPy(SUBA) films polymerized in a $0.1 \mathrm{M}$ solution with a $\mathrm{pH}$ of 13.55 (originally 3.6, but the $\mathrm{pH}$ was increased by adding $\mathrm{NaOH}$ to enhance SUBA solubility) display a difficult and depressed polymerization pattern. Similarly, it was described that conductivity of the films dramatically dropped when prepared in solutions with a $\mathrm{pH}$ higher than $6 .{ }^{55}$ In line with this, PPy(SUBA) films displayed only weak conductivity (Fig. 1f).

Bioavailability of the immobilized protein was assured with FDC-P1 cells. Both, PPy(OXA) and PPy(SUCA) films with immobilized IL-3 restore cell viability of FDC-P1 cells after IL-3 deprivation (Fig. 4b), suggesting that IL-3 was successfully immobilized on the films and accessible for the cells. However, total amount of protein immobilized, as estimated by comparative studies with FDC-P1 cells cultivated in soluble IL-3 at a known concentration (Fig. S2c, ESI $\dagger$ ), was considered rather low. This represents a major restriction in quantitative protein determination directly or indirectly with for instance the colorimetric bicinchoninic acid-based BCA assay that has a sensitivity of $0.5 \mu \mathrm{g} \mathrm{ml}{ }^{-1}{ }^{56}$ Moreover, minor non-specific protein adsorption onto the polymer films could not be prevented completely by washing with PBS for 30 minutes (Fig. S2d, ESI $\dagger$ ).

However, non-specifically bound IL-3 was considered to tightly adhere to the films and thus be influenced through changes of film redox state similar to the immobilized protein. The aim of future studies will be the refinement of the immobilization protocol, including washing protocols, to optimize the immobilized protein amounts and to minimize non-specific protein adsorption on the films. Furthermore, protein orientation and conformation were not controlled during immobilization. Hence, potential binding or recognition sites could be involved in the covalent bond between the polymer surface and the protein, rendering the latter one inactive or inaccessible for the cells, which ultimately makes it more difficult to make a defined statement about the actual amount of immobilized protein.
Much attention is nowadays being paid to the design of stimuli-responsive surfaces that facilitate the development of more realistic dynamic ECM models for various of biological and medical applications. ${ }^{22,23}$ The switching mechanism on electroactive polymer surfaces is believed to be based on conformational changes between a collapsed and fully extended protein structure (Fig. 4d). ${ }^{9}$ In principle, when the PPy film is oxidized, the immobilized protein is in closer proximity to the polymer film surface, thus is impeded from being recognized by cell surface receptors. In contrast, when fully extended, the protein is largely free from steric hindrance effects and therefore able to bind to specific cellular receptors. ${ }^{22}$

Given our data, a clear difference for cell viability between oxidized and as fabricated or reduced state of PPy(SUCA) films with immobilized IL-3 can be observed (Fig. 4c), which is not attributable to the switching procedure itself (Fig. S2e, ESI $\dagger$ ). However, the effect is still far from the desired effect obtained in starved cells that are not replenished with IL-3, neither in soluble nor matrix-bound form, indicating that the protocol for protein switching based on redox changes of the films has yet to be optimized to ensure maximum switching performance. Furthermore, it can be assumed that protein switching is not merely a binary operation but instead sensitive to several factors including media composition, in particular its protein concentration and buffer composition, as well as protein immobilization density, which ultimately induce steric hindrances and thereby affect switching efficiency. ${ }^{22,23}$

\section{Experimental section}

\section{Polymer synthesis}

The pyrrole monomers (Fluka, Switzerland) used were vacuum distilled and stored at $-20{ }^{\circ} \mathrm{C}$ prior to use. All other reagents were of analytical grade and not further purified. Prior to polymerization of the PPy films, gold-silicon (AuSi) substrates were fabricated in house using thermal evaporation (5 nm $\mathrm{Cr}$ adhesion layer and $100 \mathrm{~nm} \mathrm{Au}$ on Si wafer), cut in $1 \times$ $2 \mathrm{~cm}^{2}$ pieces, cleaned in freshly-prepared RCA-1 solution $\left(\mathrm{NH}_{3}\right.$, $\mathrm{H}_{2} \mathrm{O}_{2}$ and distilled water in $1: 1: 5$ ratio) for 5 minutes at approximately $80{ }^{\circ} \mathrm{C}$, rinsed with distilled water and blown dry with $\mathrm{N}_{2}$. Polypyrrole (PPy) films were polymerized onto AuSi substrates by electropolymerization using a three-electrode setup consisting of an $\mathrm{Ag} / \mathrm{AgCl}$ reference electrode, an AuSi substrate serving as a working electrode and a platinum coated titanium mesh as a counter electrode. During electropolymerization, each substrate was submerged in a solution consisting of $0.1 \mathrm{M}$ pyrrole in a $0.1 \mathrm{M}$ solution of the respective carboxylic acid (oxalic acid, OXA; succinic acid, SUCA; suberic acid, SUBA) or in a $0.1 \mathrm{M} \mathrm{LiClO}_{4}$ or $0.1 \mathrm{M} \mathrm{NaDBS}$ solution, resulting in a total area of $1 \mathrm{~cm}^{2}$ available for film polymerization. $\mathrm{LiClO}_{4}$ was bought from Acros (Geel, Belgium), oxalic acid from Alfa Aesar (Karlsruhe, Germany), NaDBS from TCI (Zwijndrecht, Belgium) all other carboxylic acids were bought from Sigma (Steinheim, Germany). Polymer films were generated by applying constant potential (0.7 $\mathrm{V}$ for OXA and $\mathrm{ClO}_{4}, 0.85 \mathrm{~V}$ for SUCA and SUBA, $0.7 \mathrm{~V}$ for 
$\mathrm{ClO}_{4}$, DBS) to the working electrode until a similar thickness (same color) was reached. For $\mathrm{PPy}(\mathrm{OXA})$ films this was $25 \mathrm{mC}$ of consumed charge, for PPy(SUCA) films $50 \mathrm{mC}$ and for PPy(SUBA) films $75 \mathrm{mC}$.

\section{Polymer film characterization}

Electrochemical characterization was assessed by performing $\mathrm{CV}$ and impedance measurements using an Ivium Stat.XR electrochemical analyzer coupled with the dedicated software (Ivium, Eindhoven, Netherlands). Cyclic voltammograms were recorded in $0.1 \mathrm{M} \mathrm{NaCl}$ (VWR Chemicals, Leuven, Belgium) or in solutions of the respective dopant (all $0.1 \mathrm{M}$ ) with a scan rate of $100 \mathrm{mV} \mathrm{s}^{-1}$. Impedance spectra of the films were recorded before and after protein immobilization within the frequency range of $0.05 \mathrm{~Hz}$ to $100 \mathrm{kHz}$ in $0.1 \mathrm{M} \mathrm{NaCl}$ at a bias potential of $0 \mathrm{mV} v s$. the open circuit potential (OCP). The amplitude of the applied sine wave potential was $5 \mathrm{mV}$. Surface roughness profile of the polypyrrole films was determined by using a Dektak 6 M Profilometer (Veeco Instruments Inc., NY). Wettability of the polymer samples was evaluated by measuring the static water contact angles of the films before and after protein immobilization, as well as after EDC/NHS activation using the sessile drop technique with fresh Milli-Q water (18.2 M $\Omega$ ) and a CAM200 Optical Contact Angle Meter (KVS Instrument, Helsinki, Finland) for detection. Scanning electron microscopy (SEM) images of the doped PPy films were acquired using a Leo 1550 Gemini SEM operating at $4.0 \mathrm{keV}$. Attenuated total reflectance (ATR) measurements were performed with a PIKE MIRacle ATR accessory with a diamond prism in a Vertex 70 spectrometer (Bruker, MA, USA) using a DTGS detector and the dedicated software (Opus, Bruker Optik, USA), with all measurements being performed at room temperature under continuous purging of N2.

\section{Cells}

FDC-P1 cells were routinely cultured in Iscove's modified Dulbecco's medium (IMDM; Lonza, BioWhittaker ${ }^{\circledR}$ ) supplemented with $10 \%$ heat-inactivated fetal bovine serum (FBS) (HyClone UK Ltd, Cramlington, UK), 1\% penicillin-streptomycin (each 10.000 $\mathrm{U} \mathrm{ml}^{-1}$, Lonza, BioWhittaker ${ }^{\circledR}$ ), $2 \mathrm{mM}_{\text {L-glutamine (GE }}$ Healthcare, Pasching, AT), and 5\% of an interleukin-3 (IL-3)containing supernatant. For biocompatibility and switching experiments, FDC-P1 cells were washed four times, and then cultured without IL-3 on polymer films.

\section{Biocompatibility analysis}

Annexin-V staining was performed on FDC-P1 cells stained with Alexa Fluor (AF) 647-coupled Annexin-V (Biolegend, San Diego, $\mathrm{CA}$ ) according to the manufacturer's protocol and subsequently analyzed via flow cytometry (FACSCanto, BD, USA) using the BD FACSDiva $^{\mathrm{TM}}$ software.

\section{IL-3 immobilization}

Protein immobilization onto the PPy films was performed using $N$-(3-dimethylaminopropyl)- $N^{\prime}$-ethylcarbodiimide hydrochloride (EDC)/ $N$-hydroxysuccinimide (NHS) coupling chemistry. NHS and EDC were obtained from Sigma-Aldrich (Stockholm, Sweden).
EDC (200 mM) and NHS (50 mM) were mixed freshy in distilled water prior to all experiments. For activation of the carboxyl groups, $100 \mu \mathrm{l}$ of the EDC/NHS mix (in a 4:1 molar ratio) was dropped onto the surfaces and incubated for 30 minutes. Surfaces were rinsed with distilled water and afterwards incubated with $100 \mathrm{ng} \mathrm{ml} \mathrm{m}^{-1}$ recombinant IL-3, (Peprotech, London, UK) in PBS for 2 hours at room temperature. After incubation, the films were rinsed with PBS for 30 minutes to remove excess unbound protein.

\section{IL-3 bioavailability and switching}

For validation of cytokine immobilization, bioavailability and switching, FDC-P1 cells were deprived of IL-3. Therefore, to evaluate the effect of IL-3 starvation and subsequent cytokine replenishment, FDC-P1 cells were washed thoroughly to remove all residual soluble and cell membrane-bound IL-3. For washing, 1-1.5 $\times 10^{6}$ cells were diluted in $5 \mathrm{ml}$ PBS and centrifuged at $1400 \mathrm{rpm}$ for 4 minutes (Universal 320R, Hettich, Germany). This step was repeated once again, afterwards the cells were resuspended in $0.5 \mathrm{ml}$ FBS and incubated for 5-10 minutes at room temperature. Following, $4.5 \mathrm{ml}$ PBS were added and the cells were centrifuged again. This step was repeated and after centrifugation, the cells were resuspended in complete culture medium lacking IL-3. FDC-P1 cells were cultivated either with or without murine recombinant IL-3 $\left(0.1 \mathrm{ng} \mathrm{ml}^{-1}\right)$ to investigate the effect of IL-3 deprivation. For determination of cytokine bioavailability, the modified films with immobilized IL-3 were cultivated with FDC-P1 cells for 24, 48 and 72 hours. For switchable presentation of the immobilized protein, constant positive $(0.2 \mathrm{~V})$ or constant negative $(-0.7 \mathrm{~V})$ potentials were applied to the films using portable potentiostats (EmStat, PalmSens, Netherlands) and the dedicated software (PSTrace 3.0, PalmSens, Netherlands) for 24 and 48 hours. Cell viability and proliferation was assessed by $1: 1$ trypan blue exclusion staining using $0.4 \%$ trypan blue dye (Bio-Rad, CA, USA) and an automated cell counter (TC10, Bio-Rad, CA, USA).

\section{Statistical analysis}

The statistical analysis of the results was performed with GraphPad Prism 6.0 (GraphPad Software Inc., La Jolla CA). For statistical significance, student $t$-test as well as one-way ANOVA testing were performed and $p<0.05$ was considered significant.

\section{Conclusions}

In the present study, a novel in vitro system mimicking matrixbound presentation of biomolecules to cells was established, allowing for overcoming current limitations regarding the characterization of non-soluble proteins and dissecting their implication in HSC behaviour. The obtained results further demonstrate that the presentation of immobilized IL-3 can be altered by changing the redox potential of the films, paving the way for electronic control over stem cell behaviour. However, to ensure better control over protein switching even under complex 
biological conditions, future studies regarding the electrochemical switching properties of PPy films as well as other relevant issues such as media composition and immobilized protein density are required. The developed system provides a new and interesting tool to investigate the role of surface bound proteins on both adherent and non-adherent (stem) cells. In addition to showing good cell viability and protein immobilization, the material is able to add a temporal aspect to the protein presentation that allows for more advanced cell biology studies. Likewise, the system opens up the path to develop advanced cell culture dishes or microphysiological devices that potentially allow for long term storage and expansion of stem cells. Future studies will expand towards defined cell populations from freshly isolated bone marrow as well as other sources of HSCs such as human umbilical cord blood.

\section{Conflicts of interest}

There are no conflicts to declare.

\section{Acknowledgements}

This study was supported by the Swedish Research Council (VR-2014-3079 to E. W. H. J. and VR-2012-05110 to J.-I. J.) and the Swedish Cancer Society (CAN 2015/676 to J.-I. J.). We would like to thank the European Union for funding the Erasmus+ program, thereby supporting the student exchange of J. Baumgartner. We thank Camilla Halvarsson and Emma Rörby for their great assistance in cell culture and flow cytometry as well Thomas Ederth and Thomas Lingefelt for their excellent technical assistance in ATR and SEM analysis, respectively. Moreover, we want to thank Elham Sheikhzadeh and Valerio Beni for their input on polypyrrole modifications in preliminary studies.

\section{Notes and references}

1 E. M. Green and R. T. Lee, Physiol. Rev., 2013, 93(1), 311-325.

2 X.-S. Jiang, C. Chai, Y. Zhang, R.-X. Zhuo, H.-Q. Mao and K. W. Leong, Biomaterials, 2006, 27(13), 2723-2732.

3 H. Mayani, F1000 Research, F1000 Fac. Rev., 2016, 5, 1524.

4 M. Y. Gordon, in Colopny-Stimulating factors, ed. J. M. Garland, Marcel Dekker, New York, 1997, pp. 133-144.

5 M. W. Long, R. Briddell, A. W. Walter, E. Bruno and R. Hoffman, J. Clin. Invest., 1992, 90(1), 251-255.

6 D. M. Anderson, S. D. Lyman, A. Baird, J. M. Wignall, J. Eisenman, C. Rauch, C. J. March, H. S. Boswell, S. D. Gimpel and D. Cosman, Cell, 1990, 63(1), 235-243.

7 S. Rafii, B. Heissig and K. Hattori, Gene Ther., 2002, 9(10), 631-641.

8 C. Salto, E. Saindon, M. Bolin, A. Kanciurzewska, M. Fahlman, E. W. H. Jager, P. Tengvall, E. Arenas and M. Berggren, Langmuir, 2008, 24(24), 14133-14138.

9 K. Svennersten, M. H. Bolin, E. W. H. Jager, M. Berggren and A. Richter-Dahlfors, Biomaterials, 2009, 30(31), 6257-6264.

10 X. Liu, Z. Yue, M. J. Higgins and G. G. Wallace, Biomaterials, 2011, 32(30), 7309-7317.
11 W. Khan, M. Kapoor and N. Kumar, Acta Biomater., 2007, 3(4), 541-549.

12 Z. Zhang, Y. Liang, P. Liang, C. Li and S. Fang, Polym. Int., 2011, 60(4), 703-710.

13 G. F. Khan and W. Wernet, Thin Solid Films, 1997, 300(1), 265-271.

14 H. Peng, C. Soeller, N. A. Vigar, V. Caprio and J. TravasSejdic, Biosens. Bioelectron., 2007, 22(9-10), 1868-1873.

15 H. Peng, C. Soeller, N. Vigar, P. A. Kilmartin, M. B. Cannell, G. A. Bowmaker, R. P. Cooney and J. Travas-Sejdic, Biosens. Bioelectron., 2005, 20(9), 1821-1828.

16 V. Serafin, L. Agui, P. Yanez-Sedeno and J. M. Pingarron, Biosens. Bioelectron., 2014, 52, 98-104.

17 Z. Bagheryan, J.-B. Raoof, M. Golabi, A. P. F. Turner and V. Beni, Biosens. Bioelectron., 2016, 80, 566-573.

18 E. Sheikhzadeh, M. Chamsaz, A. P. F. Turner, E. W. H. Jager and V. Beni, Biosens. Bioelectron., 2016, 80, 194-200.

19 R. Wadhwa, C. F. Lagenaur and X. T. Cui, J. Controlled Release, 2006, 110(3), 531-541.

20 A. Herland, K. M. Persson, V. Lundin, M. Fahlman, M. Berggren, E. W. H. Jager and A. I. Teixeira, Angew. Chem., Int. Ed., 2011, 50, 12529-12533.

21 E. Cantini, X. Wang, P. Koelsch, J. A. Preece, J. Ma and P. M. Mendes, Acc. Chem. Res., 2016, 49(6), 1223-1231.

22 C. L. Yeung, X. Wang, M. Lashkor, E. Cantini, F. J. Rawson, P. Iqbal, J. A. Preece, J. Ma and P. M. Mendes, Adv. Mater. Interfaces, 2014, 1(2), 1300085.

23 M. Lashkor, F. J. Rawson, J. A. Preece and P. M. Mendes, Analyst, 2014, 139(21), 5400-5408.

24 J. Y. Wong, R. Langer and D. E. Ingber, Proc. Natl. Acad. Sci. U. S. A., 1994, 91, 3201.

25 A. Gelmi, M. J. Higgins and G. G. Wallace, Biomaterials, 2010, 31, 1974.

26 A. J. Evans, et al., J. Biomed. Mater. Res., Part A, 2009, 91, 241.

27 J. H. Collier, J. P. Camp, T. W. Hudson and C. E. Schmidt, J. Biomed. Mater. Res., 2000, 50, 574.

28 D. H. Kim, S. M. Richardson-Burns, J. L. Hendricks, C. Sequera and D. C. Martin, Adv. Funct. Mater., 2007, 17, 79.

29 X. Cui and D. C. Martin, Sens. Actuators, B, 2003, 89, 92.

30 J.-W. Lee, F. Serna, J. Nickels and C. E. Schmidt, Biomacromolecules, 2006, 7, 1692.

31 N. Gomez and C. E. Schmidt, J. Biomed. Mater. Res., Part A, 2007, 81, 135.

32 D. Melling, S. A. Wilson and E. W. H. Jager, RSC Adv., 2015, 5, 84153.

33 M. Nishizawa, T. Kitazume and H. Kaji, Electrochemistry, 2008, 76, 532.

34 O. Berezhetska, B. Liberelle, G. De Crescenzo and F. Cicoira, J. Mater. Chem. B, 2015, 3, 5087.

35 X. Liu, Z. Yue, M. J. Higgins and G. G. Wallace, Biomaterials, 2011, 32, 7309.

36 E. Smela, J. Micromech. Microeng., 1999, 9(1), 1-18.

37 E. W. H. Jager, E. Smela and O. Inganas, Science, 2000, 290(5496), 1540-1545. 
38 M. Golabi, A. P. F. Turner and E. W. H. Jager, Macromol. Chem. Phys., 2016, 217(10), 1128-1135.

39 R. Rasuli, Z. Mokarian, R. Karimi, H. Shabanzadeh and Y. Abedini, Thin Solid Films, 2015, 589, 364-368.

40 M. Hu, J. Yan, Y. He, H. Lu, L. Weng, S. Song, C. Fan and L. Wang, ACS Nano, 2010, 4(1), 488-494.

41 A. A. Leme, C. M. Vidal, L. S. Hassan and A. K. BedranRusso, J. Biomech., 2015, 48(10), 2067-2071.

42 C. A. Harris, J. H. Resau, E. A. Hudson, R. A. West, C. Moon, A. D. Black and J. P. McAllister, J. Biomed. Mater. Res., Part A, 2011, 98(3), 425-433.

43 T. M. Dexter, J. Garland, D. Scott, E. Scolnick and D. Metcalf, J. Exp. Med., 1980, 152, 1036.

44 K. M. Sakamoto, S. Grant, D. Saleiro, J. Crispino, N. Hijiya, F. Giles, L. Platanias and E. A. Eklund, Mol. Genet. Metab., 2015, 114(3), 397-402.

45 T. Nakashima, Y. Kobayashi, S. Yamasaki, A. Kawakami, K. Eguchi, H. Sasaki and H. Sakai, Biochem. Biophys. Res. Commun., 2000, 275(3), 768-775.

46 I. G. Denisov, A. Y. Shih and S. G. Sligar, J. Inorg. Biochem., 2012, 108, 150-158.

47 S. Jeon, J. M. Moon, E. S. Lee, Y. H. Kim and Y. Cho, Angew. Chem., Int. Ed., 2014, 53(18), 4597-4602.
48 K. J. Gilmore, M. Kita, Y. Han, A. Gelmi, M. J. Higgins, S. E. Moulton, G. M. Clark, R. Kapsa and G. G. Wallace, Biomaterials, 2009, 30(29), 5292-5304.

49 H. Zhang, K. Wang, Y. Xing and Q. Yu, Mater. Sci. Eng., C, 2015, 56, 564-573.

50 A. Fahlgren, C. Bratengeier, A. Gelmi, C. M. Semeins, J. Klein-Nulend, E. W. H. Jager and A. D. Bakker, PLoS One, 2015, 10(7), e0134023.

51 P. M. George, A. W. Lyckman, D. A. LaVan, A. Hegde, Y. Leung, R. Avasare, C. Testa, P. M. Alexander, R. Langer and M. Sur, Biomaterials, 2005, 26(17), 3511-3519.

52 S. H. Bauquier, K. J. McLean, J. L. Jiang, R. C. Boston, A. Lai, Z. Yue, S. E. Moulton, A. J. Halliday, G. Wallace and M. J. Cook, Macromol. Biosci., 2017, 17, 5.

53 S. B. Saidman, J. Electroanal. Chem., 2002, 534(1), 39-45.

54 M. Zhou and J. Heinze, J. Phys. Chem. B, 1999, 103(40), 8443-8450.

55 W. Wernet, M. Monkenbusch and G. Wegner, Mol. Cryst. Liq. Cryst., 1985, 118(1), 193-197.

56 P. K. Smith, R. I. Krohn, G. T. Hermanson, A. K. Mallia, F. H. Gartner, M. D. Provenzano, E. K. Fujimoto, N. M. Goeke, B. J. Olson and D. C. Klenk, Anal. Biochem., 1985, 150(1), 76-85. 